\title{
Interventional relevance and retrofit programming: Concepts for the improvement of clinician acceptance of computer-generated assessment reports
}

\author{
JAMES H. JOHNSON, THOMAS A. WILLIAMS, \\ DANIEL E. KLINGLER, and RONALD A. GIANNETTI \\ Veterans Administration Hospital, Salt Lake City, Utah 84148, and \\ University of Utah College of Medicine, Salt Lake City, Utah 84148
}

\begin{abstract}
A brief historical review of research on the use of computers in mental health service delivery is presented. The computer-assisted psychiatric assessment project (PAU) at the Salt Lake City VA Hospital is briefly described in the perspective of previous research. It is noted that the initial design for the PAU was deficient in the development of a computer-generated reporting scheme which is totally acceptable to clinicians. Two conceptual innovations, interventionally relevant reporting and retrofit programming, are introduced. These are described as providing solutions to the problem of obtaining clinician acceptance of computer-generated assessment reports. Pilot research on the use of these concepts is presented.
\end{abstract}

An increasingly important area of clinical research involves the use of computer technology in mental health service delivery. In a recent review of the research in this area (Johnson, Giannetti, \& Williams, 1976), three consecutive developmental stages were identified. In the first stage, computer vendors worked together with mental health administrators to develop automated patient data systems which emphasized administrative applications, such as the reduction and consolidation of paper chart material. The Camarillo State Hospital system (Graetz, 1966), the Multi-State Information System (Laska, Logemann, \& Weinstein, 1971), the Missouri Standard System of Psychiatry (Sletten, Ulett, $\&$ Hedlund, Note 1), the Computer Support in Military Psychology System (Morgan, Note 2), and Institute of Living system (Glueck, 1974) are examples of this work. In the second stage of development, research shifted from administrative to clinical concerns. The goal of this research was to determine whether standard clinical techniques could be automated. Examples of such research include automation of the MMPI (Gilberstadt, 1969), Rorschach (Piotrowski, 1964), WAIS (Elwood \& Griffin, 1972), mental status interview (Colby, Watt, \& Gilbert, 1966), social history (Laska, 1974), and nursing notes (Rosenberg \& Glueck, 1969). In the most recent stage of research in this area, behavioral scientists have attempted to use computers as tools for complex decision making in mental health care delivery. Pioneering research in this area has been

Requests for reprints should be addressed to James $\mathrm{H}$. Johnson, Systems and Evaluation Unit, VA Hospital, Salt Lake City, Utah 84148. undertaken both at the Missouri and Institute of Living projects. A prototypic example of this work involves using the computer and its data base for the assignment of psychotropic drugs (Altman, Evenson, Sletten, \& Cho, 1974). Other similar research efforts include projects that attempted to predict the likelihood of treatment success (Mirabile, Houck, \& Glueck, 1971), length of stay (Altman, Angle, Brown, \& Sletten, 1972), elopement (Altman, Brown, \& Sletten, 1972), and the danger of the patient to others (Hedlund, Sletten, Altman, \& Evenson, 1973).

The on-line computer-assisted Psychiatric Assessment Unit (PAU) at the VA Hospital in Salt Lake City is perhaps the most comprehensive example of a decisionoriented system. This system was designed and implemented after a thorough analysis of the mental health care delivery system (Cole, Johnson, \& Williams, 1975; Williams, Johnson, \& Bliss, 1975). The PAU was developed using an on-line computer system, so that patient data could be gathered and interpreted fast enough for real-time clinical decision making. Part of the data are gathered directly from patients (Cole, Johnson, \& Williams, 1976) using interactive cathode-ray tube terminals (CRTs). Other data are collected by paraprofessional personnel who, prompted by schedules on the CRTs, enter information into the system. The computer analyzes all data and generates assessment reports. The system makes use of on-line computer technology to complete a timely, inexpensive, and comprehensive evaluation of psychological, medical, and social problems, which is useful for intake decision making (Johnson, Giannetti, \& Williams, 1975; Johnson \& Williams, 1975). Results of preliminary evaluation research on the system have shown that it reduces treatment staff work loads, 
results in decisions which compare favorably with those rendered by experienced clinicians, and appeals to patient users (Klingler, Johnson, \& Williams, 1976), and, further, that it produces patient assessments which are rated by experienced psychiatrists as equal or superior to standard clinical reports (Klingler, Miller, Johnson, \& Williams, Note 3).

It is evident from this brief introductory discussion that most of our previous research has aimed at developing and operationalizing a computer-assisted process for the assessment of applicants for mental health care at the VA Hospital in Salt Lake City. We have implemented a system which is conceptually innovative in that it, unlike most previous systems, was developed to meet the decision-making needs of a mental health service delivery agency. In large measure, we have met our developmental aims. More than 3,000 patients have been assessed with on-line computer instrumentation, and the PAU is firmly established as a part of the health care delivery system at the institution.

However, while it is fair to say that we have operationalized a conceptually innovative system, it is also important to note that the components of the PAU system are relatively standard psychological and health care assessment tools. Well known and well researched instruments are included in the assessment package. These have been automated on an individual basis. In our initial design, it was decided that the clinical coordinator would gather the individual assessment reports, review findings, and integrate results for use in triage decision making and as a basis for the initial treatment plan. It was our assumption that this design would allow us to avoid problems in the acceptance of computer-generated reports by clinicians that are anecdotally known to have hindered progress with previous systems (Johnson, Giannetti, \& Williams, 1976).

In the process of implementing the PAU and obtaining clinician feedback about the computerized reporting system, we have learned (to our dismay) that, while this approach results in improved overall assessment procedures (Klingler, Miller, Johnson, \& Williams, Note 3), it does not satisfy all the demands of our working clinicians. The approach of using test-bytest computerized reporting with a clinical coordinator's summary provides a wealth of data, but also seems to result in information overload. The treatment clinicians require information specific to the patient that is easily obtainable. The large, poorly integrated data base generated by the PAU is at cross purposes with this need. Additionally, the PAU system leads to highly standardized reports which, our clinicians complain, are boring to read. Therefore, we have come to believe that a different approach to the problem will be required to bring about total clinician acceptance. As we have previously noted (Giannetti, Klingler, Johnson, \&
Williams, 1976), on-line computer technology provides a fundamentally different medium from the traditional paper-and-pencil medium for assessment procedures. Data manipulation schemes on a computer assessment system can and should be much more sophisticated than traditional approaches.

The purpose of this paper is to acquaint those interested in on-line assessment research with initial work bearing on two new concepts related to clinician acceptance of computerized reports that have grown out of our work: interventionally relevant automated assessment and retrofit programming. Research on the improvement of on-line assessment has important implications for the delivery of mental health services. In a recent survey of 66 randomly chosen mental health treatment facilities (community mental health centers and VA, university, state, and private inpatient wards), $48 \%$ of those questioned responded that they were interested in the development of a computer-assisted assessment system. If these figures are indicative of present interest levels, then it can be expected that there will be an enormous increase in this type of research over the next several years. We feel that it is essential that others considering research and development efforts on systems similar to PAU be cognizant of these concepts prior to undertaking such work if continued progress in the field is to be maintained.

\section{CONCEPTUAL DESCRIPTION}

\section{Interventional Relevance}

The concept of interventional relevance is broad in scope. It applies generally to assessment, but particularly to computerized assessment because of the social demands for accountability where large monetary expenditures are involved. Interventionally relevant assessment differs from traditional descriptive assessment in that its rationale rests with the direct impact that it has on decision making. Where descriptive assessment aims at providing information to be used by the clinician in decision making, interventionally relevant assessment aims at providing information on which the decision specifically turns.

Behavioral scientists have traditionally used assessment strategies aimed at descriptive reporting. Despite experimental data which have led to doubts about the value of traditional descriptive procedures (Cline, 1964; Kostlan, 1954; Sines, 1959), many clinicians continue to agree with Klein and Davis (1969) that extensive descriptive assessment of patients is required for adequate clinical care.

Beginning with the work of Cronbach and Gleser (1965), however, behavioral scientists have begun to emphasize that assessment gains utility from its impact on decision making, rather than from its reliability and validity for description. A number of investigators have 
undertaken preliminary research on the development of predictive schemes which would have relevance for treatment decision making (Barraclough, Bunch, Nelson, \& Sainsbury, 1974; Gurel \& Lorei, 1973; Harman \& Raymond, 1970; Lester, 1970; Mirabile, Houck, \& Glueck, 1971; Paykel, Prusoff, \& Myers, 1975; Schwartz, Myers, \& Astrachan, 1974; Serban \& Gidynski, 1975; Shaffer, Perlin, Schmidt, \& Stephens, 1974; Strauss \& Carpenter, 1972). However, while pioneering research has been important in delineating the possibilities of interventionally relevant datagathering strategies, it has heretofore been impossible to make effective use of such approaches because health care settings have not had systems in place which would allow for routine application in the patient care process. The advent of the computerized-assessment approach makes the development of interventionally relevant procedures feasible for routine application in health care settings. Because a uniform and extensive data base of quantified variables is routinely gathered at intake, it is possible, for the first time, to consider interactions between intake descriptions and outcome events in settings dedicated to clinical applications. A computer-assisted admission system makes it possible to consider a wide range of intake data to increase the probability of discovering interventionally relevant relationships, and, further, to use the interventionally relevant relationships in day-to-day patient care to augment the more traditional descriptive reporting procedures.

\section{Retrofit Programming}

For most readers, the concept of retrofit programming is new. Unlike "interventional relevance," it is not a broadly applicable term; rather, it is highly specific to the problem of computerized assessment. The term "retrofit" was coined by the present authors to describe a solution to a programming problem which has plagued behavioral scientists doing research on computerized assessment. Computer-generated reports lack the individuality of reports prepared by clinicians. Although computerized reports do contain individualized information, the framework is standardized according to the tests administered, rather than according to the problems of the patient. Computerized systems, such as PAU, are comprehensive, but lack integration. The total assessment report consists of a series of individual assessment instrument interpretations. These are integrated by a clinician who provides a written summary of the various diverse reports. The concept of retrofit programming implies that the computer itself will synthesize data around the individual patient. In the retrofit approach, data continue to be gathered and initially reported on a test-by-test basis. However, one of the assessment devices becomes a "key" indicator around which all other results are organized. Interpretative output from all instruments is coded as input for a final, individually tailored report. Using the interpretation for the key instrument as a base, interpretative materials from all other procedures are consolidated into a final report of supporting or conflicting data relevant to the key material. In this way, material from the disparate instruments are retrofit (fit backward) to the individual being assessed.

Prior to the advent of computerized assessment systems, there was very little interest in clinical reporting procedures. In a search of the scientific literature, we were able to find only two reports (Hammond \& Allen, 1953; Huber, 1961) bearing directly on this topic. Clinical care is typically undertaken on a highly individualistic basis. Therefore, attention to the details of reporting style is seen as unnecessary or tangential. In our experience with the development of the PAU, however, we have come to believe that consideration of the details of reporting style is crucial to the user acceptance of reports generated by a computer.

Our earlier review of the literature (Johnson, Giannetti, \& Williams, 1976) indicated that previous and present computerized systems in psychiatry make use of reporting systems which are organized according to what Huber (1961) describes as the "most primitive of topical outlines.... [an] outline in which the tests themselves are the topics" (p. 27). Huber prefers a chronological, topical format which focuses on behavior disorders in relation to personality strengths and follows the sequence of present, past, and future. Hammond and Allen (1953) suggest two modifications: a contact paragraph which states the main problem and an opening summary that outlines the major points of the detailed body. Neither the PAU nor any other computerized assessment system in psychiatry presently uses this type of reporting format. To develop this reporting scheme on a computer system, it is necessary to use a retrofit approach, whereby individual test results are first interpreted individually and then amalgamated backward around a key instrument.

\section{PILOT RESEARCH}

\section{Interventionally Relevant Assessment}

Our initial interest in the development of interventionally relevant assessment strategies evolved out of our efforts to implement the PAU system. The PAU concept depended heavily on self-report information for decision making. Therefore, it was important that we gather information regarding the veracity of data obtained in this manner. Moreover, the comprehensive assessment completed on each patient was purchased at a cost in patient time, and in staff and computer resources. It seemed an unnecessary waste of both patient time and institutional resources to have patients completing self-report questionnaires when results would be of doubtful validity. What was needed was a brief screening device that would provide results relevant 
to the decision, "Should the patient undergo computerized self-report testing?" To fill this need, we undertook construction of our first interventionally relevant assessment device, a PAU validity scale (the Q1).

Construction and validation of the $Q 1$. The initial form of the PAU validity screening instrument consisted of 223 items taken from the MMPI validity scales or written by PAU staff members. This instrument was administered to a sample of 73 patients. Scores were recorded for the $\mathrm{L}, \mathrm{F}$, and $\mathrm{K}$ scales of the MMPI, along with clinical interview ratings for fake good, fake bad, grossly psychotic, patient obtunded, overall validity, rated accuracy of a standard MMPI interpretation, and correctness of response to a subset of MMPI items $(20,36,158,215$, and 294). Each of the 223 validity items was correlated with the external validity measures. If an item correlated nonzero with any of the validity measures at the $\alpha=.05$ level, the item was retained in the second form of the validity battery. For the second form of the questionnaire, new validity items were written by PAU clinical staff to augment the item pool remaining from the initial analysis. This resulted in a new instrument of 146 items which was administered to 56 patients. External validity measures were obtained as in the initial analysis. Validity items were again correlated with the MMPI and interviewer validity ratings. Using the $\alpha=.05$ critical level for retaining items, the third form of the validity scale was constructed from the 36 items exhibiting significant nonzero correlations.

Data were obtained from 155 patients, using the third form of the validity scale. The 36 -item intercorrelation matrix was computed and factor analyzed by the principal axes method with iteration to stable communality estimates. Inspection of the eigenvalue spectrum suggested a unifactorial solution. Those 18 items having factor loadings greater than .30 were chosen to form the $Q 1$ validity scale. These items are shown in Table 1.

The reliability estimation technique used was KuderRichardson Formula 20 (Gulliksen, 1950). For the third form sample of 155 patients, the sum of the item variances was 2.45 ; the scale variance was 11.85 . Thus, an upperbound estimate of scale reliability for the 18-item test is .84 .

The stability of the PAU validity scale was confirmed by a cross-validation of the factor analytic results. A second sample of 43 patients was used in an attempt to replicate the pattern of coefficients on the first principal axis. Following extraction of the first principal axis, an index of factorial congruence was computed. This index was equal to .80 . Given the small variable to number of subjects ratio, this was seen as satisfactory evidence of cross-validity of the item structure.

A cut-off score for "fake bad" was then established at one standard deviation above the mean, using the
Table 1 Items of the Q1 Validity Indicator

1. Evil spirits possess me at times.

2. Everybody lies; the only difference is that some don't get caught.

3. Most any time I would rather sit and daydream than to do anything else.

4. "Cattlepens have ball points" is a statement that makes sense.

5. At one or more times in my life I felt that someone was making me do things by hypnotizing me.

6. A "paradox" is two doctors.

7. My soul sometimes leaves my body.

8. It is safer to sleep with your clothes on.

9. My body is here but my spirit is not.

10. I cannot get attention by being kind to people.

11. There is something basically wrong with my mind and there always will be.

12. I can get attention by casting out demons.

13. Someone has been trying to rob me.

14. "Traduce" is a good poker hand.

15. When these tests get too long, I sometimes just go down the rows marking answers randomly.

16. I never answer questions honestly.

17. There are particular questions that I object to.

18. These are not simple questions for me to answer true or false to.

cross-validation sample as the normative group. As an external measure of the validity of the scale, it was hypothesized that results from the Q1 should correlate significantly with other well known indicators of validity, such as the $F-K$ index (Gough, 1950) on the MMPI. A new sample of 479 male patients assessed by the PAU was obtained. They were administered a Q1 and MMPI (Miller, Johnson, Klingler, Williams, \& Giannetti, Note 4) via the computerized system. Data were analyzed and subjects were divided into "faking" and "not faking" groups for both the Q1 and the $\mathrm{F}-\mathrm{K}$ index ("fake bad" determined by an index score of 9 or greater). The phi coefficient of correlation was computed between $Q 1$ and $F-K$ findings. Results were highly significant $(.49, \mathrm{p}<.001)$. To further analyze the data, optimal "fake bad" cut-off points were empirically derived for the sample. Using "fake bad" cut-off points of $(\mathrm{Q} 1)>5$ and $(\mathrm{F}-\mathrm{K})>8,73 \%$ of the subjects in the sample had scores on both $Q 1$ and $F-K$ which were not considered "fake bad." Together, the findings suggest that the Q1 is useful for the decision, "Will the patient give valid computerized self-report information?"

Treatment-relevant indicators. Given our success in the development of the Q1 as an indicator of selfreport validity, we began to consider other questions which had direct interventional relevance and which could be answered by information gathered by an intake assessment system. The following decisions appeared most relevant to intervention at the time of intake into a mental health care delivery system: Should a given patient be treated in an inpatient or an outpatient setting? Is psychopharmacological therapy 
indicated? If so, which medication is most likely to to be appropriate for this patient? Are there special considerations, such as suicide risk, which must be taken into account in developing adequate initial treatment plans? What is the most likely outcome of treatment? What is the most likely long-term prognosis? Is this patient likely to require readmission at some future time? In reviewing the PAU system of individual descriptive measures, it became obvious that none of the existing procedures was specifically relevant to providing answers to questions such as these.

Therefore, we began to pursue the development of decision-relevant assessment strategies. A sample of patients tested by the PAU during late 1973 and early 1974 was chosen for study. Information was abstracted from patient charts regarding various aspects of treatment, hospital course, and outcome, as related to the questions formulated above. Using summary level data such as scale scores available from the standard PAU clinical base data, 48 intake variables were selected by experienced clinicians on the basis they might be related to the interventionally relevant questions. Using the SPSS statistical package, several step-wise regression analyses were completed in an attempt to relate the data. Where relationships were discovered between intake data and patient outcomes, regression equations were developed in order to explore the possibility of prediction in future cases. The results of the preliminary analyses are presented in Table 2.

Results of the analyses presented in Table 2 indicate that such predictions can be made at levels that significantly exceed chance. While levels of association are not such that perfect predictions can be made, it appears that information of this type can offer incremental validity for intake decision making and initial treatment planning by clinicians. Therefore, we are now designing a simple report which will summarize the interventionally relevant predictive information. An example of an initial version of the report is presented in Table 3. In this report, intake information is presented concisely by converting results of linear equations into probability statements about an individual patient. Assuming that

Table 2

Results of Step-Wise Regression Analyses for Treatment-Relevant Predictions

\begin{tabular}{lccc}
\multicolumn{4}{c}{ Treatment-Relevant Predictions } \\
\hline \multicolumn{1}{c}{ Prediction } & $\begin{array}{c}\text { Number } \\
\text { of Cases }\end{array}$ & $\begin{array}{c}\text { Multi- } \\
\text { ple I }\end{array}$ & r Square \\
\hline Inpatient/Outpatient Assignment & 290 & .41 & .17 \\
Suicide Gesture & 290 & .40 & .16 \\
Good Response-Antipsychotic & 290 & .47 & .23 \\
Good Response-Mood Elevators & 290 & .34 & .12 \\
Good Response-Lithium & 290 & .26 & .07 \\
Good Response-Minor Tranquilizer & 290 & .38 & .14 \\
Days Hospitalized & 290 & .42 & .18 \\
Hospital Course & 152 & .35 & .12 \\
Prognosis & 58 & .77 & .59 \\
Recidivism & 290 & .28 & .08 \\
\hline
\end{tabular}

Table 3

Example of an Interventionally Relevant Report

PATIENT NAME: JOHN DOE

DATE: $11 / 14 / 76$

PROBABILITY OF INPATIENT TREATMENT

PROBABILITY OF SUICIDE IDEATION OR GESTURE DURING HOSPITALIZATION

$75 \%$ $12 \%$ PROBABLE PREFERRED MEDICATION: ANTIPSYCHOTIC EXPECTED NUMBER OF INPATIENT DAYS: 10 PROBABILITY OF FAVORABLE HOSPITAL COURSE: $60 \%$ PROBABILITY OF FAVORABLE PROGNOSIS: PROBABILITY OF RECIDIVISM DURING NEXT 24 MONTHS: $60 \%$ $15 \%$

we are able to cross-validate the regression equations on a new sample of patients, we hope to establish such a report as part of our standard PAU output.

\section{Retrofit Programming}

Just as with our early work on interventionally relevant assessment procedures, our interest in retrofit reporting evolved quite naturally during the course of implementing the PAU system. A problem in clinician acceptance of computer-generated reports became apparent soon after the PAU system was operational. Clinicians found computer-generated reports boring to read. We had considered this problem in the initial design of the system (Johnson, Cole, \& Williams, 1975), but had underestimated the difficulties in attempting to derive a solution. Although the standardized framework of computerized reports does contain individualized information, staff members find the standardized framework repetitive, no matter how unique the individualized information. Detailed information about patient problems is presented in a routine format and is not emphasized according to the particular patient's situation or need. The standardized framework of reporting has led to questions about the applicability of computerized reports for clinical care. Feedback from treatment staff, such as, "I want to know that information first which pertains to the patient's treatment. I do not want to have to look through several pages of a report to find the specific information which is important for the treatment of my patient," directed us to the concept of retrofit data manipulation. Our clinicians were requesting a reporting format that accented the information central to the treatment of the individual patient.

An initial attempt to correct this problem involved the development of a summary sheet, an example of which is illustrated by Table 4 . The aim was to summarize on a single piece of paper the most relevant results of the most frequently used intake assessment instruments. While this summary represented an initial effort to improve the organization of descriptive reporting, it did little to individually tailor report generation to highlight the most important findings for the individual patient. 
Table 4

PAU Assessment Summary Sheet

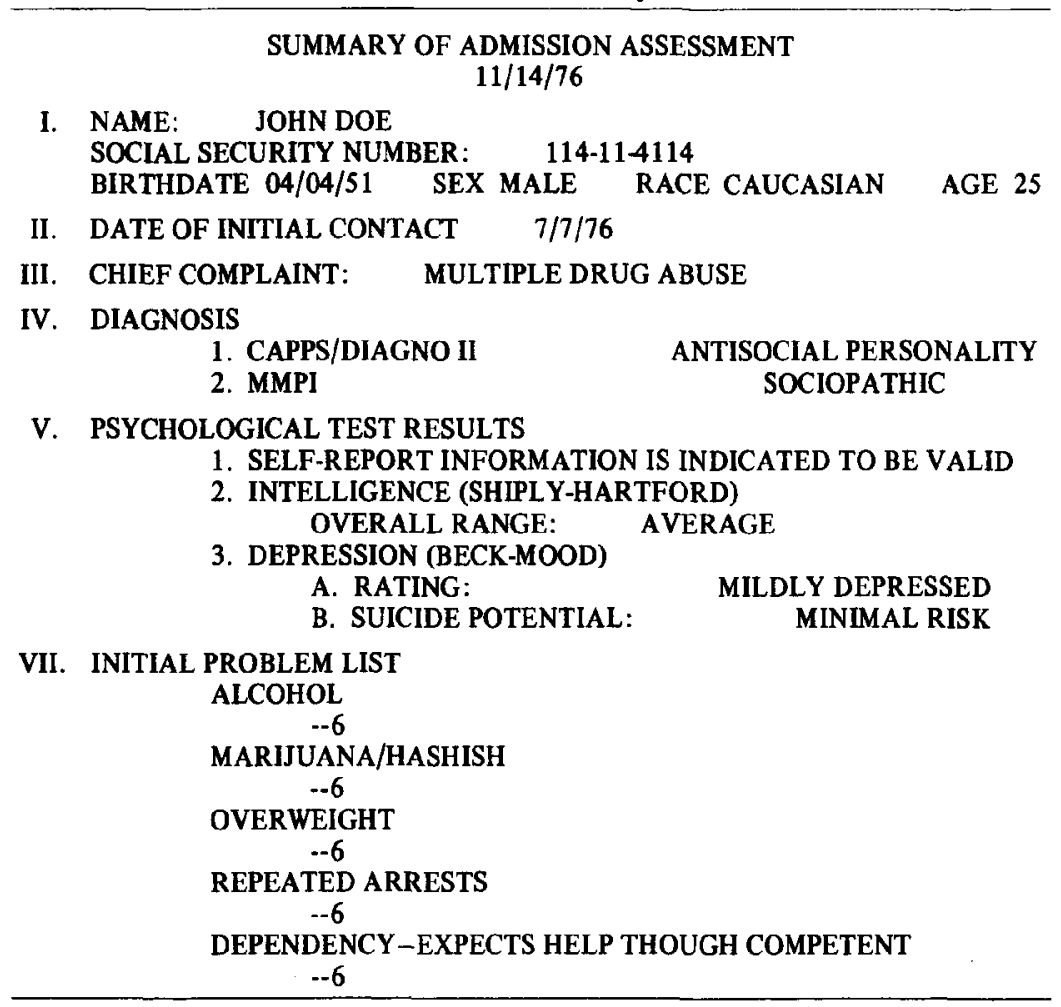

We are now working on a tailored reporting scheme which we hope will result in improved clinician acceptance and utilization of intake assessment data. The new system utilizes a retrofit programming scheme. The retrofit programming system is dependent upon the patient-flow system through the PAU. A patient is initially seen by an intake clinician who elicits information about the history of his illness. Technicians complete computerized physical and mental status examinations on the patient. The patient then interacts directly with the computer, using a CRT for collection of self-report data. Upon completion of the datagathering phase, the patient returns for a final interview with the intake clinician. The clinician and patient review preliminary reports from individual assessment instruments. Based upon the assembled reports and the review meeting, the intake clinician constructs a problem list (Giannetti, Johnson, Williams, \& McCusker, Note 5) for the patient. Severity level is rated for relevant problems that are selected from a structured list, and information is entered directly into the computer system via a CRT. The computer sorts the problems according to the rating of severity and a disability weight (derived by a previous Q-sort technique), and generates a problem list. The problem list is the basis of the retrofit approach that is under development. Each output statement from each computerized assessment report will be rationally precoded as to its relationship to each output statement of the structured problem list. Therefore, for the individual patient, output results from each test can be related as supportive or nonsupportive of the individual problems specified. Because of this, it is possible for the computer to generate a tailored descriptive report which is organized according to the problems of the specific patient, rather than according to the instruments administered to the patient. The individually tailored report, which will replace all preliminary instrumentspecific reports, will be forwarded with the patient, as the descriptive component of PAU reporting that augments interventionally relevant reporting, for use by treatment clinicians. However, test-specific reports will be available to the clinicians should they desire additional information about the test results or disagree with the PAU-formulated problem list.

Systems design for the retrofit programming can be described briefly. All possible output statements from all assessment procedures will be precoded by experienced clinicians for relevance to all possible items in the problem list dictionary. A master report format will be developed so that the initial section will describe the most important problems and the consistency or lack of consistency among the various assessment procedures. Following the individually tailored section of the report, other pertinent descriptive information will be presented. An example of the format 
Name: Age: Date:

Circumstances of Admisstion:

(free form from intake clinician)

History of Present Illness:

(free form from intake clinician)

Assessment Report:

Primary Problems. At the time of admission the patient's primary problems were

tent with these problems, and which are not usually seen as consistent with these problems.
wesults from psychological testing with the MMPI (are, are not) in general agreement with
the above. They suggest a person who

Results obtained from other psychological testing (are, are not) consistent with the patient's primary problens.

According to the patient's self-report history, there are several aspects of his life which may be important for the treatment of these problens.

Other Relevant Information. Current signs and symptoms:

Prevlous signs and symptoms:

Psychological test scores:

Previous mental health treatment history:

Current patfent Information:

1. Living conditions:

2. Family support system:

3. Vocational and avocation competency:

4. Recent stressors:

5. General personality style:

Other patient information:

1. Family history:

2. Childhood history:

3. Adult history:

Self-report problems:

Diagnostic condition: Using the DIAGNO-II algorfthm, the patient is diagnosed as than others seen at PAU.

This lllness is relatively (areater, sintlar, less) in severity

Figure 1. Skeleton for individually tailored report. 
is presented in Figure 1. As proposed, the retrofit programming scheme will edit assessment results for consistency and relate the results to an individually tailored reporting format derived from the list of primary problems. All other relevant assessment results will be amalgamated into the remainder of this single assessment report. Only positive or relevant negative findings will be noted.

In Table 5, an example of part of the final output from retrofit data manipulation is shown. The tailored report accents the individual's problems, rather than presenting a standardized report. For this example, the initial portion consists of free-form input from the clinician. Following the free-form heading, the various other computerized assessment results are amalgamated into a unified report about the patient.

Currently, we are in the process of completing design work for an operational version of the individually tailored report. It is our belief that this type of reporting better mimics the more valuable aspects of standard clinician reporting, and will, therefore, result in improved clinician acceptance of computer-derived assessments.

\section{DISCUSSION}

In the process of implementing and using an on-line computer-assisted psychiatric assessment system, we have developed two conceptual innovations which we believe will be helpful for improving clinician acceptance of computer-generated reporting: interventionally relevant reporting and retrofit programming. To our knowledge, the proposed solutions for the problem of clinician acceptance of computer-generated assessment reports in mental health care are the first to be presented in the scientific literature. While many other problems in the area of computerized assessment have received experimental treatment, the problem of clinician acceptance of computerized report generation (which is known, at least anecdotally, by researchers working in this area) seems to have been neglected. In our experience, the problem of clinician acceptance of computerized reports is one of the most difficult problems to solve in this area of research. Therefore, we are concentrating research efforts on this topic, and are hopeful that this paper will stimulate others into similar research.

Table 5

Initial Sections of an Example Tailored Report

\begin{tabular}{llll}
\hline NAME: JOHN DOE & RACE: CAUCASION & AGE: 25 & DATE: $11 / 14 / 76$
\end{tabular}

CIRCUMSTANCES OF ADMISSION:

THE PATIENT WAS BROUGHT TO THE HOSPITAL BY HIS WIFE (FROM WHOM HE IS SEPARATED) AFTER THREATENING TO KILL HIMSELF WITH A 12 GAUGE SHOTGUN. AT THE TIME OF APPLICATION FOR CARE HE WAS ORIENTED TIMES THREE, BUT SHOWED EXTREMELY RETARDED AFFECT.

\section{HISTORY OF PRESENT ILLNESS:}

THE PATIENT HAS A HISTORY WHICH INCLUDES A NUMBER OF DEPRESSIVE EPISODES BEGINNING AT AGE 17 AND ONE PREVIOUS HOSPITALIZATION FOR DEPRESSION IN MAY 1973. THE PRESENT EPISODE WAS PRECIPITATED SIX WEEKS AGO FOLLOWING A MARITAL ARGUMENT AFTER WHICH HIS WIFE MOVED OUT.

\section{ASSESSMENT REPORT:}

PRIMARY PROBLEMS. AT THE TIME OF ADMISSION THE PATIENTS PRIMARY PROBLEMS WERE DEPRESSION, AUDITORY HALLUCINATION, AND SUICIDAL IDEATION. THE INTERVIEWER OBSERVED GUILT, MARKED ALCOHOL ABUSE, OBSESSIONAL THINKING, AND SUSPICIOUSNESS WHICH WERE CONSISTENT WITH THESE PROBLEMS.

RESULTS FROM PSYCHOLOGICAL TESTING WITH THE MMPI ARE IN GENERAL AGREEMENT WITH THE ABOVE. THEY SUGGEST A PERSON WHO IS SEEN AS MANIFESTING MULTIPLE NEUROTIC SYMPTOMS WHICH INCLUDE DEPRESSION, NERVOUSNESS, ANXIETY, WEAKNESS, FATIGUE, LACK OF INITIATIVE AND A PERVASIVE LACK OF SELF-ESTEEM, AND SELF-CONFIDENCE. SUCH INDIVIDUALS ARE PESSIMISTIC WORRIERS, GUILT RIDDEN AND INTROPUNITIVE, GENERALLY FEARFUL AND OBSESSIVELY PREOCCUPIED WITH THEIR PERSONAL DEFICIENCIES. WHEN THEIR NEED FOR ACHIEVEMENT IS FRUSTRATED, THEY USUALLY RESPOND BY SELF BLAME AND NEUROTIC GUILT FEELINGS.

RESULTS OBTAINED FROM OTHER PSYCHOLOGICAL TESTING ARE CONSISTENT WITH THE PATIENTS PRIMARY PROBLEMS. WHILE THE BECK MOOD SCORE SUGGESTS ONLY MODERATE DEPRESSION (UPPER 25 PER-CENT OF THIS POPULATION), THE BECK HOPELESSNESS SCALE SCORE IS CONSISTENT WITH SUICIDAL BEHAVIOR (UPPER 5 PER-CENT OF THIS POPULATION).

THE ROTTER SUGGESTS A PERSON WHO SEES REWARDS AND PUNISHMENTS AS OUTSIDE OF HIS CONTROL AND WHO IS DEPENDENT ON POWERFUL EXTERNAL FACTORS.

THE DIFFERENTIAL PERSONALITY QUESTIONNAIRE INDICATES A TENDENCY TO WORRY, TO BECOME UPSET, OR TO BE NERVOUS. SUCH PEOPLE VIEW THEMSELVES AS PRONE TO RUN INTO BAD LUCK AND FEEL A LACK OF HELP AND COOPERATION FROM OTHERS. THEY TEND NOT TO BE AGGRESSIVE OR STRIKE BACK WHEN WRONGED. 


\section{REFERENCE NOTES}

1. Sletten, I. W., Ulett, G. A., \& Hedlund, J. L. Standard systems of psychiatry [S.S.O.P.]. St. Louis: Department of Psychiatry at Missouri Institute of Psychiatry, 1973 (Spring Abbreviated Edition).

2. Morgan. D. W. Computer support in military psychiatry [COMPSY]. Annual Progress Report No. 3, 1 January 1971. 31 December 1971. Washington, D.C: Walter Reed Army Medical Center, 1972.

3. Klingler, D. E., Miller, D. A., Johnson, J. H., \& Williams, T. A. Process evaluation of an on-line computer assisted unit for intake assessment of mental health patients. Paper presented at the Sixth Annual Meeting of the National Conference on the Use of On-line Computers in Psychology, St. Louis, November 1976.

4. Miller, D. A., Johnson, J. H., Klingler, D. E., Williams, T. A., \& Giannetti, R. A. Design for an on-line computerized system for MMPI interpretation. Paper presented at the Sixth Annual Meeting of the National Conference on the Use of On-line Computers in Psychology, St. Louis, November 1976.

5. Giannetti, R. A., Johnson, J. H., Williams, T. A., \& McCusker, C. F. Development of an on-line problemoriented system for the evaluation of mental health treatment services. Paper presented at the Sixth Annual Meeting of the National Conference on the Use of On-line Computers in Psychology, St. Louis, November 1976.

\section{REFERENCES}

Altman, H., Angle, H. V., Brown, M. L., \& Sletten, I. W. Prediction of length of hospital stay. Comprehensive Psychiatry, 1972, 13, 471-480.

Altman, H., Brown, M. L., \& Sletten, I. W. "And.. silently steal away": A study of elopers. Diseases of the Nervous System, 1972, 33, 52-58.

Altman, H., Evenson, R. C., Sletten, I. W., \& Cho, D. W. Computer predictions of psychotropic drug assignment in state mental facilities: Effects of eliminating alcoholics from the study sample. Diseases of the Nervous System, 1974, 35, 505-508.

Barraclough, B., Bunch, J., Nelson, B., \& Sainseury, P. A hundred cases of suicide: Clinical aspects. British Journal of Psychiatry, 1974, 125, 355-373.

CLINE, V. B. Interpersonal perception. In B. A. Maher (Ed.), Progress in experimental personality research (Vol. 1). New York: Academic Press, 1964.

Colby, K. M., Watt, J. B., \& Gilbert, J. P. A computer method of psychotherapy: Preliminary communication. Journal of Nervous and Mental Disease, 1966, 142, 148-152.

Cole, E. B., Johnson, J. H., \& Williams, T. A. Design considerations for an on-line computer system for automated psychiatric assessment. Behavior Research Methods \& Instrumentation, 1975, 7, 195-198.

Cole, E. B., Johnson, J. H., \& Williams, T. A. When psychiatric patients interact with on-line computer terminals: Problems and solutions. Behavior Research Methods \& Instrumentation, 1976, 8, 92-94.

Cronbach, L. J., \& Gleser, G. C. Psychological tests and personnel decisions. Urbana: University of Illinois Press, 1965.

Elwood, D. L., \& Griffin, H. R. Individual intelligence testing without the examiner: Reliability of an automated method. Journal of Consulting and Clinical Psychology, 1972, 38, 9-14.

Giannetti, R. A., KlingleR, D. E., Johnson, J. H., \& Wrlliams, T. A. The potential for dynamic assessment systems using on-line computer technology. Behavior Research Methods \& Instrumentation, 1976, 8, 101-103.
Gilberstad, H. Construction and application of MMPI code books. In J. N. Butcher (Ed.), MMPI: Research developments and clinical applications. New York: McGraw-Hill, 1969.

Glueck, B. C. Computers at the institute of living. In J. L. Crawford, D. A. Morgan, D. T. Gianturco (Eds.), Progress in mental health information systems: Computer applications. Cambridge, Mass: Ballinger, 1974.

Gougr, $H$. $G$. The $F$ minus $K$ dissimulation index for the MMPI. Journal of Consulting Psychology, 1950, 14, 408-413.

GRAETz, R. E. The computer: A new tool for psychiatry. Hospital and Community Psychiatry, 1966, 17, 26-28.

Gulliksen, H. Theory of mental tests. New York: Wiley, 1950.

GURE L, L., \& LoREI, T. W. The labor market and schizophrenics' posthospital employment. Joumal of Counseling Psychology, 1973, 20, 450-453.

Hammond, K. R., \& Allen, J. M., JR. Writing clinical reports. New York: Prentice-Hall, 1953.

Harman, C. E., \& RaYmond, C. S. Computer prediction of chronic psychiatric patients. Journal of Nervous and Mental Disease, 1970, 150, 490-503.

Hedlund, J. L., Sletten, I. W., Altman, H., \& Evenson, R. C. Prediction of patients who are dangerous to others. Journal of Clinical Psychology, 1973, 29, 443-447.

HUBER, J. T. Report writing in psychology and psychiatry. New York: Harper \& Brothers, 1961.

Johnson, J. H., Cole, E. B., \& Williams, T, A. PROSE: A simple user-oriented program for computer constructed narratives. Behavior Research Methods \& Instrumentation, $1975,7,309-310$.

Johnson, J. H., Giannettr, R. A., \& Williams, T. A. Realtime psychological assessment and evaluation of psychiatric patients. Behavior Research Methods \& Instrumentation, 1975, 7, 199-200.

Johnson, J. H., Giannetti, R. A., \& Williams, T. A. Computer in mental health care delivery: A review of the evolution toward interventionally relevant on-line processing. Behavior Research Methods \& Instrumentation, 1976, 8, 83-91.

Johnson, J. H., \& Williams, T. A. The use of on-line computer technology in a mental health admitting system. American Psychologist, 1975, 30, 388-390.

Klein, D. F., \& Davis, J. M. Diagnosis and drug treatment of psychiatric disorders. Baltimore: Williams \& Wilkins, 1969.

KiIngler, D. E., Johnson, J. H., \& Williams, T. A. Strategies in the evaluation of an on-line computer-assisted unit for intake assessment of mental health patients. Behavior Research Methods \& Instrumentation, 1976, 8, 95-100.

Kostlan, A. A method for the empirical study of psychodiagnosis. Journal of Consulting Psychology, 1954, 18, 83-88.

LASKA, E. The multi-state information system. In J. L. Crawford, D. W. Morgan, \& D. T. Gianturco (Eds.), Progress in mental health information systems: Computer applications. Cambridge, Mass: Ballinger, 1974.

Laska, E., Logemann, G. W., \& Weinstein, A. The multi-state information system for psychiatric patients. Transactions of the New York Academy of Sciences, $1971,33,780.790$

Lester, D. Attempts to predict suicidal risk using psychological tests. Psychological Bulletin, 1970, 74, 1-17.

Mirabile, C. A., Houck, J. H., \& Glueck, B. C., JR. Computer prediction of treatment success. Comprehensive Psychiatry, 1971, 12, 48-53.

PAykel, E. S., Prusoff, B. A., \& Mrers, J. K. Suicide attempts and recent life events. Archives of General 
Psychiatry, 1975, 32, 327-333.

Piotrowsxi, Z. A digital-computer interpretation of inkblot test data. Psychiatric Quarterly, 1964, 38, 1-26.

RosenberG, M., \& GLUECK, B. C. Automation of behavioral observations on hospitalized psychiatric patients. Hospital Topics, 1969, 47, 27-28.

Schwartz, C. C., MYers, J. K., \& Astrachan, B. M. Psychiatric labeling and the rehabilitation of the mental patient. Archives of General Psychiatry, 1974, 31, 329-334.

Serban, G., \& Gidrnski, C. B. Differentiating criteria for acute-chronic distinction in schizophrenia. Archives of General Psychiatry, 1975, 32, 705-712.
Shaffer, J. W., Perlin, S., Schmidt, C. W., JR., \& Stephens, J. H. The prediction of outcome in schizophrenia. Journal of Nervous and Mental Disease, 1974, 159, 349-355.

SINES, L. K. The relative contribution of four kinds of data to accuracy in personality assessment. Journal of Consulting Psychology, 1959, 23, 483-492.

Strauss, J. S., \& Carpenter, W. T. The prediction of outcome in schizophrenia. Archives of General Psychiatry, 1972, 27, 739-746.

Williams, T. A., Johnson, J. H., \& Bliss, E. L. A computerassisted psychiatric assessment unit. American Journal of Psychiatry, 1975, 132, 1074-1076. 